\title{
Fast Release of Sulfosalicylic Acid from Polymer Implants Consisting of Regenerated Cellulose $/ \gamma$-Ferric Oxide/Polypyrrole
}

\author{
Nargis A. Chowdhury, ${ }^{1}$ John Robertson, ${ }^{2}$ Ahmed Al-Jumaily, ${ }^{1}$ and Maximiano V. Ramos ${ }^{3}$ \\ ${ }^{1}$ Institute of Biomedical Technologies, Auckland University of Technology, St. Paul Street, Wellesley Campus, \\ Auckland 1142, New Zealand \\ ${ }^{2}$ School of Applied Sciences, Auckland University of Technology, St. Paul Street, Wellesley Campus, Auckland 1142, New Zealand \\ ${ }^{3}$ School of Engineering, Auckland University of Technology, St. Paul Street, Wellesley Campus, Auckland 1142, New Zealand
}

Correspondence should be addressed to Nargis A. Chowdhury; nargis.afroj@aut.ac.nz

Received 24 September 2014; Revised 27 November 2014; Accepted 28 November 2014; Published 22 December 2014

Academic Editor: Luqman Chuah Abdullah

Copyright (c) 2014 Nargis A. Chowdhury et al. This is an open access article distributed under the Creative Commons Attribution License, which permits unrestricted use, distribution, and reproduction in any medium, provided the original work is properly cited.

\begin{abstract}
This work presents a comparative study on the rate of drug release from implantable matrices induced by electric and magnetic fields separately for better biomedical applications. The matrices were prepared by coating $\gamma$-ferric oxide dispersed regenerated cellulose film by polypyrrole doped with sulfosalicylic acid as an anti-inflammatory drug. The drug release mechanisms were studied under both the electric and the magnetic fields separately in an acetate buffer solution with pH 5.5 and temperature $37^{\circ} \mathrm{C}$ during a period of 5 hours. The amount of drug released was analysed by UV-Vis spectrophotometry. The mechanism of drug release from the matrices under electric field includes expansion of conductive polymer chain and the electrostatic force between electron and drug. The drug release mechanism from the matrices under magnetic field is based on the fact that the heat produced locally by magnetic particles loosens the polymer (polypyrrole) chain surrounding the particles. As a result, the drugs attached to the polypyrrole chain come out to the release medium. The matrices showed fast release of drug, that is, more than $60 \%$ of the loaded drug was released within $1 \mathrm{~h}$, and are ideal for the treatment of illness in an emergency care.
\end{abstract}

\section{Introduction}

The existing drug delivery devices based on microelectromechanical systems (MEMS) technology are experiencing some challenges because of their low delivery rates and high power consumption. Several implantable drug delivery devices have been investigated for the treatment of chronic diseases. The drug release mechanism from the devices is based on diffusion and a complete release is achieved within 10-15 hours. Current implantable drug delivery devices are not capable of delivering drugs for immediate treatment of illnesses in an emergency care. The challenge lies in the development of implantable devices for emergency treatments that require rapid and reliable rate of drug delivery [1].

In 2005, Maloney et al. developed a reservoir-typed drug delivery system that relies on electrothermal actuation. The reservoir under electrical field allows the drugs to be diffused freely from the reservoirs to the region of interest [2].
The supply of actuating energy requires either implantation of a battery or electrical leads that cause discomfort to the patient's skin. These problems can be overcome if the drug delivery matrices are actuated magnetically.

In recent years, researchers are trying to develop materials that are both magnetic and electrically conductive and can be used as suitable substrates for drug delivery when stimulated by electric and/or magnetic fields [3]. Electrically conductive macromolecules such as polypyrrole containing metal oxide nanoparticles have been prepared and investigated [4]. However, these nanocomposites possess low electrical conductivity, low magnetization values, and lack of well-defined shape. For drug delivery, and so forth, the nanoparticles must have the combined properties of high magnetic saturation, biocompatibility, and interactive functions at the surface [5].

In this study, we present a rapid drug delivery system consisting of regenerated cellulose $/ \gamma$-ferric oxide/polypyrrole matrices as transdermal implants for patients include angina 
and muscle pain. Cellulose is known as the earth's major biopolymer and has economic importance globally. In this study, regenerated cellulose is used for developing drug delivery matrices as it is biocompatible and more environmentally friendly than synthetic electroactive polymers [6]. In addition, polypyrrole is used to coat the $\gamma$-ferric oxide nanoparticles dispersed regenerated cellulose matrices as $\gamma$ ferric oxide nanoparticles can undergo rapid biodegradation when they are directly integrated in a biological system [7]. Moreover, regenerated cellulose has a strong affinity to polypyrrole which makes it with improved electrical conductivity [8]. The main advantages of using $\gamma$-ferric oxide are that the material is super paramagnetic with low toxicity and can be manufactured in large scale $[9,10]$. The drug delivery matrices containing $\gamma$-ferric oxide nanoparticles can be activated magnetically because of the super paramagnetic nature of $\gamma$-ferric oxide nanoparticles. These magnetically induced drug delivery devices gain patients compliance as that does not damage healthy tissue. The principle of controlled drug release from regenerated cellulose/magnetic particles composite under magnetic field is based on the fact that heat produced locally by magnetic particles under alternating current $(\mathrm{AC})$ magnetic field loosens the polymer chain surrounding the particles at temperatures above the glass transition temperature (Tg) of that particular composite, resulting in drugs being released [11]. Magnets in association with carriers containing super paramagnetic iron oxide nanoparticles (SPION) help in delivering drug to inflammatory sites at a desired rate and allow switching on and off the magnetic field, thus targeting the particles at the local site [12]. Gamma ferric oxide nanoparticles having diameter $<50 \mathrm{~nm}$ are termed as SPION. They have magnetic properties because of the presence of aligned unpaired electron spins. Their moments align with the direction of the magnetic field while being placed under magnetic field. As a result, it enhances magnetic flux and the rate of drug release [9].

Chemical compounds used in this paper are as follows: $\mathrm{Fe}\left(\mathrm{NO}_{3}\right)_{3} \cdot 9 \mathrm{H}_{2} \mathrm{O}$ (ferric nitrate nonahydrate) (PubChem CID-24527), polyethylene glycol (PEG1000) (PubChem CID-174), and potassium chloride (KCl) (PubChem CID-4873); lithium chloride, cotton linter (DPW 4580), pyrrole (PPy) (PubChem CID-8027), 5-sulfo-salicylic acid dihydrate (PubChem CID-2723734), ferric chloride hexahydrate (PubChem CID-24810), dimethylacetamide (DMAC) (PubChem CID-31374), 2-propanol (PubChem CID-3776), acetone (PubChem CID 180), and methanol (PubChem 887).

\section{Matrices Synthesis}

2.1. Synthesis of Gamma Ferric Oxide Nanoparticles. Gamma ferric oxide $\left(\gamma-\mathrm{Fe}_{2} \mathrm{O}_{3}\right)$ nanoparticles were prepared as follows [13]. First, $0.006 \mathrm{~mol} \mathrm{Fe}\left(\mathrm{NO}_{3}\right)_{3} \cdot 9 \mathrm{H}_{2} \mathrm{O}$ was dissolved in $100 \mathrm{~mL}$ aqueous solution of PEG1000 with a $\mathrm{NO}_{3}{ }^{-} / \mathrm{PEG} 1000$ molar ratio of 1 . Then, $0.45 \mathrm{~g} \mathrm{KCl}$ was added to the above solution. The resulting transparent solution was stirred by a magnetic stirrer and heated at $70^{\circ} \mathrm{C}$ until a homogeneous sol-like solution was formed. The sol-like solution was then dried at $110^{\circ} \mathrm{C}$ for $2 \mathrm{~h}$. After that, the obtained gel was kept in a silica crucible and heated in air until the gel was ignited. The resulting as-burned powder was boiled in deionized water to remove the salt. Finally, the products were obtained after filtering and washing with deionized water and ethanol, followed by drying at $80^{\circ} \mathrm{C}$ for $2 \mathrm{~h}$.

\subsection{Preparation of Gamma Ferric Oxide Nanoparticles Dis-} persed RC Films. $0.60 \mathrm{~g} \gamma-\mathrm{Fe}_{2} \mathrm{O}_{3}$ nanoparticles was added in $10 \mathrm{~mL}$ regenerated cellulose solution [14] and then sonicated for $4 \mathrm{~h}$. From the prepared mixture, $3 \mathrm{~mL}$ was poured on a glass petri dish to cast each film. The films thus obtained were allowed to stand in air overnight to remove the solvent. Afterwards, the films were cured in a mixture of isopropanol and deionized water $(60: 40)$. Finally, the films were dried in air.

2.3. Loading of Drugs into the Matrices. Drugs were loaded into the matrices by chemical linkages during coating the matrices with polypyrrole. The method of synthesis is described as follows. $\mathrm{RC} / \gamma-\mathrm{Fe}_{2} \mathrm{O}_{3}$ matrices were coated with polypyrrole by the chemical synthesis using $\mathrm{FeCl}_{3} / 5$ sulfosalicylic acid at 2:1 ratio as oxidant/dopant in aqueous solution. 5-Sulfosalicylic acid dihydrate acts as a model anion drug as well as a dopant. $0.03 \mathrm{~mol}$ of freshly distilled pyrrole monomer and $0.015 \mathrm{~mol}$ of the model drug were dissolved in $50 \mathrm{~mL}$ of distilled water. The mixture was stirred vigorously for $15 \mathrm{~min}$ at $0^{\circ} \mathrm{C}$ in an ice bath. $0.03 \mathrm{~mol}$ of $\mathrm{FeCl}_{3}$ in $50 \mathrm{~mL}$ distilled water was slowly added to the mixture solution at a rate of $5 \mathrm{~mL} / \mathrm{min}$ and the temperature was maintained at $0^{\circ} \mathrm{C}$. After that, $\mathrm{RC} / \gamma-\mathrm{Fe}_{2} \mathrm{O}_{3}$ matrices were immersed in $50 \mathrm{~mL}$ of the mixture solution in a glass petri dish and left for $24 \mathrm{~h}$ at $0^{\circ} \mathrm{C}$. Polypyrrole was formed slowly and deposited on the surface of the matrices. Finally, polypyrrole coated matrices were washed with water, methanol, and acetone and dried in a vacuum environment for $24 \mathrm{~h}$ [15].

\subsection{Drug Release Experiments}

2.4.1. Preparation of Acetate Buffer Solution. $150 \mathrm{~g}$ sodium acetate was dissolved in $1 \mathrm{~L}$ of distilled water. Glacial acetic acid (approximately $15 \mathrm{~mL}$ ) was then added slowly with stirring until a $\mathrm{pH}$ of 5.5 was reached.

2.4.2. Actual Drug Content. The actual amounts of drug in the $\mathrm{RC} / \gamma-\mathrm{Fe}_{2} \mathrm{O}_{3} /$ PPySSA (sulfosalicylic acid doped PPy) matrices with the dimension of $2.4 \mathrm{~cm} \times 0.6 \mathrm{~cm} \times 67-70 \mu \mathrm{m}$ were determined by dissolving the drug in the samples in $2 \mathrm{~mL}$ dimethyl sulfoxide (DMSO) and after that $0.5 \mathrm{~mL}$ of the solution was added to $3 \mathrm{~mL}$ of the acetate buffer solution. The amount of drug in the buffer solution was measured with the UV/Visible spectrophotometer at $298 \mathrm{~nm}$.

2.4.3. Diffusion Studies under Electric Field. Diffusion studies in vitro were carried out using a set-up shown in Figure 1. A drug-loaded matrix attached to negative electrode was placed in $5 \mathrm{~mL}$ acetate buffer solution of $\mathrm{pH} 5.5$ at $37^{\circ} \mathrm{C}$. Electric potentials ( 0 and $1 \mathrm{~V}$ ) were applied across the cathode and another carbon anode. The drug was diffused through 


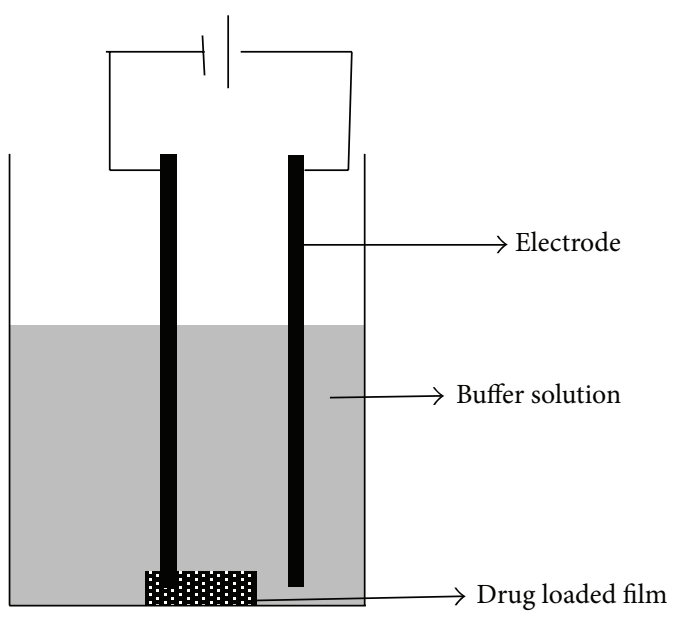

FIGURE 1: Experimental set-up used to study electroresponsive drug delivery from implants.

the matrix into the buffer solution. The total diffusion period was $5 \mathrm{~h}$. A sample of $1 \mathrm{~mL}$ of the buffer solution was withdrawn and an equal amount of fresh buffer solution was added to the cell. The UV-Visible spectrophotometer was used to measure the drug concentrations in the samples at the wavelength of $298 \mathrm{~nm}$.

2.4.4. Spectrophotometric Analysis of Model Drug. The maximum absorption spectra of the model drug were recorded using a Shimadzu UV-2101PC scanning spectrophotometer. The absorption at a $\lambda_{\max }$ of $298 \mathrm{~nm}$ was used to determine the amount of drug released from the predetermined calibration curve.

2.4.5. Diffusion Studies under Alternating Current Magnetic Field. To study drug release behaviour under an alternating current magnetic field (ACMF) an electromagnetic field was produced using a magnet with a diameter of $35 \mathrm{~mm}$ at approximately $0.1 \mathrm{~A}$ and $1.15 \mathrm{KHz}$.

\section{Results and Discussion}

3.1. Matrices Characterization. Physical, electrical, chemical, and morphological properties of the matrices were analysed in terms of degree of swelling, conductivity, infrared absorption spectra, and scanning electron microscope (SEM) images.

The degree of swelling was measured by immersing the matrices in acetate buffer solution of $\mathrm{pH} 5.5$ at $37^{\circ} \mathrm{C}$ for $72 \mathrm{~h}$ [16]. The matrices were then removed, pressed between a tissue paper, and weighed. Finally, the matrices were dried at room temperature and weighed again. The degree of swelling was determined by the water content of the matrices. Percentage degree of swelling was calculated by the following equation:

$$
\frac{M-M_{d}}{M_{d}} \times 100,
$$

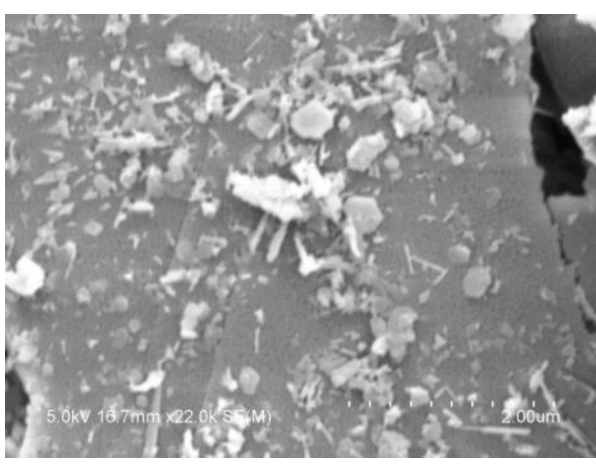

FIgURE 2: SEM image of gamma ferric oxide dispersed RC matrix.

where $M$ is weight of the $\mathrm{RC} / \gamma-\mathrm{Fe}_{2} \mathrm{O}_{3} /$ PPySSA sample after submersion in the acetate buffer solution and $M_{d}$ is weight of the sample after removing the solvent. $\mathrm{RC} / \gamma-\mathrm{Fe}_{2} \mathrm{O}_{3} /$ PPySSA matrices showed degree of swelling of $50 \%$. The result indicates the porous structure of the matrices. Drug release from the matrices involves the following processes: (i) entry of water into the matrices, (ii) swelling of the matrices, and (iii) dissolution and diffusion of the drug towards the outside of the matrices. Therefore, the porosity and the degree of swelling can play an important role to release the drug from the matrices. The particles of the water soluble drug dissolve rapidly and generate numerous pores through which the other drug molecules reach the release medium, increasing the release rate of the drug [17].

Magnetic nanoparticles themselves may not be very useful in practical applications because they tend to form large aggregates and can undergo rapid biodegradation when they are directly integrated in a biological system [7]. This study presents suitable methods of how to (i) make the particles fully dispersed in a polymer matrix and (ii) coat the particles with polypyrrole for practical applications. The distribution of gamma ferric oxide $\left(\gamma-\mathrm{Fe}_{2} \mathrm{O}_{3}\right)$ nanoparticles in the $\mathrm{RC} / \gamma-\mathrm{Fe}_{2} \mathrm{O}_{3}$ matrix was examined by the image of SEM. SEM image (Figure 2) shows that gamma ferric oxide nanoparticles can be dispersed into the cellulose matrix. However, some agglomerated particles are observed. This is because of the moisture content in some part of the sample [18]. In addition, there is hydrophobic interaction between the $\gamma-\mathrm{Fe}_{2} \mathrm{O}_{3}$ nanoparticles; as a result, these particles agglomerate and form large clusters. These clusters, then, exhibit strong magnetic dipole-dipole attractions between them and show ferromagnetic behaviour [19].

Electrical conductivity $\left(\sigma_{s}\right)$ of the $\mathrm{RC} / \gamma-\mathrm{Fe}_{2} \mathrm{O}_{3} / \mathrm{PPySSA}$ matrices was calculated by the following equation:

$$
\sigma_{s}=\frac{\Delta I}{\Delta V} \frac{l}{w d},
$$

where $l$ is length, $w$ is width, $d$ is thickness, and $\Delta I / \Delta V$ is the slope of the current versus voltage curve.

The electrical conductivity of the $\mathrm{RC} / \gamma-\mathrm{Fe}_{2} \mathrm{O}_{3} / \mathrm{PPySSA}$ film is $1.7 \times\left(10^{0} \mathrm{~S} / \mathrm{cm}\right)$, and it is eight orders of magnitude higher compared to the conductivity of $\mathrm{RC}\left(10^{-8} \mathrm{~S} / \mathrm{cm}\right)$. 


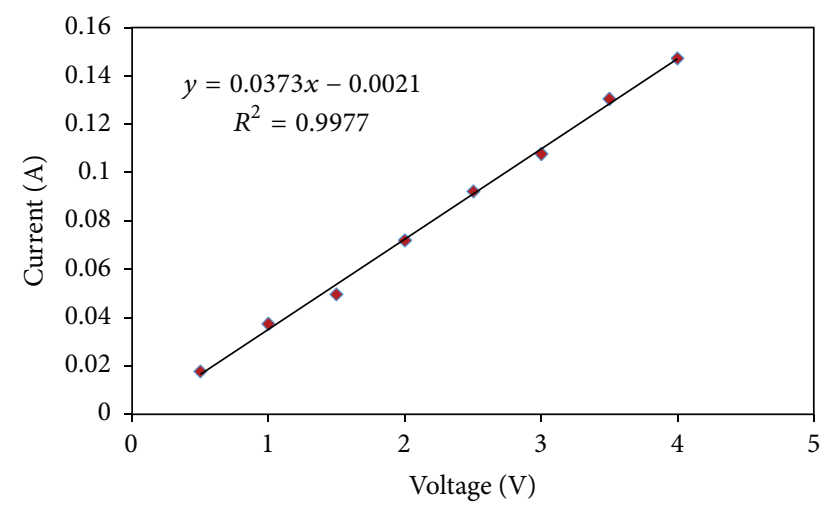

FIgURE 3: Current versus voltage curve for $\mathrm{RC} / \gamma-\mathrm{Fe}_{2} \mathrm{O}_{3} / \mathrm{PPySSA}$ matrix film, $y=$ current, $x=$ voltage, and $R^{2}=$ correlation coefficients.

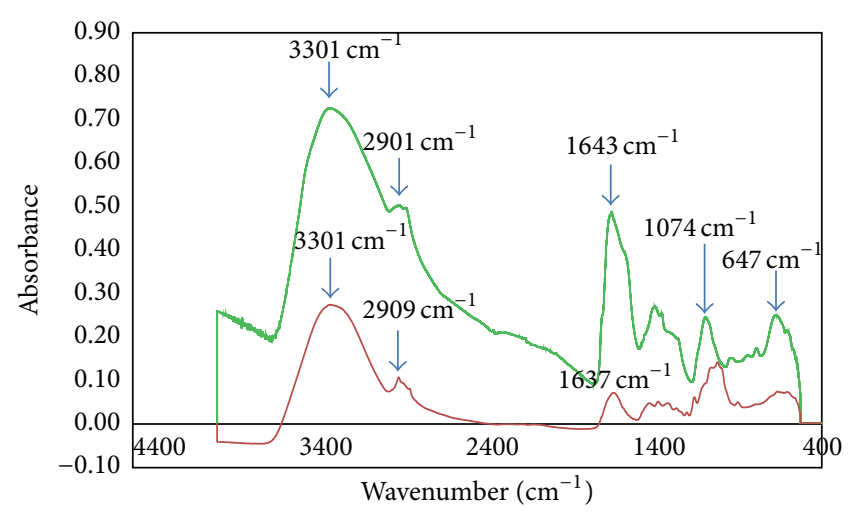

FIGURE 4: FTIR spectra of $\mathrm{RC} / \gamma-\mathrm{Fe}_{2} \mathrm{O}_{3}$ (red line) matrices film and $\gamma$ - $\mathrm{Fe}_{2} \mathrm{O}_{3}$ (green line) powder.

Figure 3 shows the typical current-voltage sweep curve. The conductivity of the matrix follows Ohm's law.

Infrared absorption studies were performed aiming to ascertain the metal-oxygen bond and the vibrational peaks of $\gamma-\mathrm{Fe}_{2} \mathrm{O}_{3}$. In Figure 4, $\mathrm{RC} / \gamma-\mathrm{Fe}_{2} \mathrm{O}_{3}$ film shows absorption peak at $3301 \mathrm{~cm}^{-1}$. This is due to the $-\mathrm{OH}$ group of $\mathrm{RC}$. The peak at $647 \mathrm{~cm}^{-1}$ of $\gamma-\mathrm{Fe}_{2} \mathrm{O}_{3}$ corresponds to the metaloxygen vibrational modes of the spinel compound [18]. In addition, $\gamma-\mathrm{Fe}_{2} \mathrm{O}_{3}$ shows absorption band in the region of $3600-3100 \mathrm{~cm}^{-1}$ relating to antisymmetric and symmetric $-\mathrm{OH}$ stretching and may be assigned for water of adsorption. Hydrates are also absorbed in the region of $1670-1600 \mathrm{~cm}^{-1}$ relating to $-\mathrm{OH}$ bending [20].

In Figure 5, the peak at $2834 \mathrm{~cm}^{-1}$ is associated with fivemembered $\mathrm{C}-\mathrm{H}$ ring stretching. These observations confirm that the PPy layer is successfully introduced onto the surface of the $\mathrm{RC} / \gamma-\mathrm{Fe}_{2} \mathrm{O}_{3}$ matrices. The peak at $998 \mathrm{~cm}^{-1}$ is for sulfonate groups $\left(\mathrm{SO}_{3}{ }^{-}\right)$stretching and the $-\mathrm{OH}$ stretching peak has a slight shift between 3000 and $3600 \mathrm{~cm}^{-1}$. These results suggest the $\mathrm{H}$-bonding between the sulfonate groups of sulfosalicylic acid and with the amine group of pyrrole unit of PPy [21].

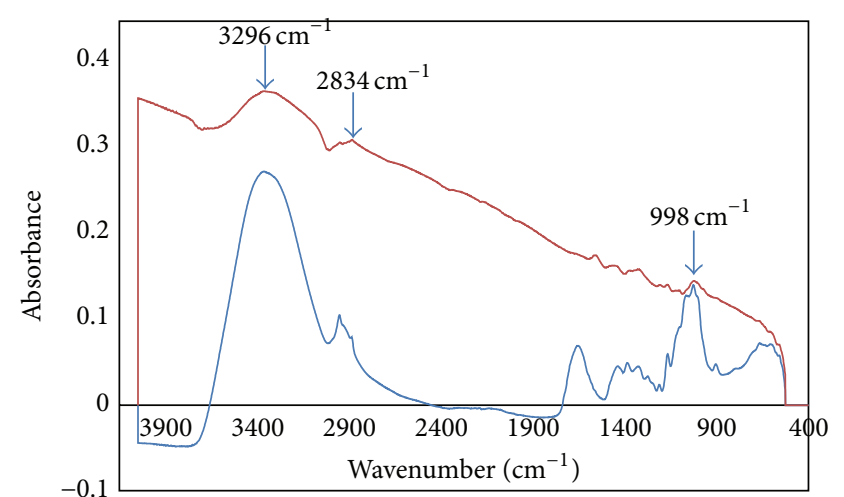

FIGURE 5: Comparison of FTIR spectra of $\mathrm{RC} / \gamma-\mathrm{Fe}_{2} \mathrm{O}_{3}$ (blue line) and $\mathrm{RC} / \gamma-\mathrm{Fe}_{2} \mathrm{O}_{3} /$ PPySSA (red line).

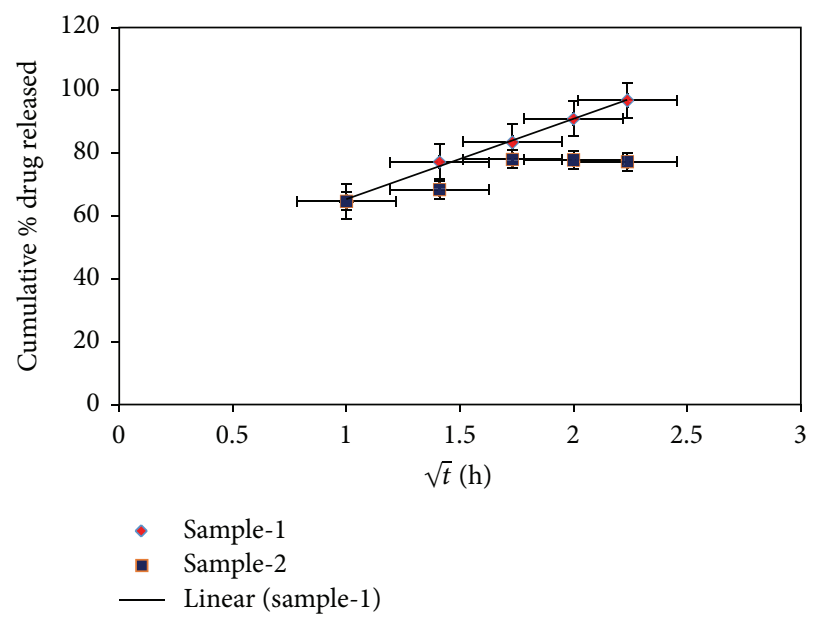

FIGURE 6: Square-root-of-time release kinetics observed by the sample-1 (1 volt) and sample-2 (0 Volt).

3.2. Kinetics of Drug Release Profile. Initially, the amount of drug present in the matrices was measured. The amount of drug present in the matrices is about $85.4 \pm 0.78 \%$. In vitro release data were fitted to various kinetic models such as zero order, first order, Higuchi release, and KorsmeyerPeppas to evaluate the mechanism of drug release without and under electric field separately [22-25]. The rate constants $(K)$ were calculated from the slope of the respective plots and high correlation $\left(R^{2}\right)$ was observed for the Higuchi model (Table 1). The values of the slope of the Korsmeyer-Peppas model determine the type of drug release mechanism.

The diffusion coefficients of sulfosalicylic acid from the matrices at 0 and 1 volts were calculated from the slope of plots of drug accumulation versus square-root-of-time according to the Higuchi equation [26]:

$$
Q=2 M_{0} \sqrt{\left(\frac{D t}{\pi}\right)}
$$

where $Q$ is the amount of material flowing through a unit cross-section of barrier in unit time, $t, M_{0}$ is the initial drug concentration in the matrices, and $D$ is the apparent diffusion coefficient of the drug. 
TABLE 1: Fitting parameters of the in vitro release data to various release kinetic models for $\mathrm{RC} / \gamma-\mathrm{Fe}_{2} \mathrm{O}_{3} / \mathrm{PPySSA}$ matrices.

\begin{tabular}{|c|c|c|c|c|c|}
\hline Samples & Order & $\begin{array}{l}\text { Electric field } \\
\text { strength }(\mathrm{V})\end{array}$ & Slope & K & $R^{2}$ \\
\hline \multirow{4}{*}{$\mathrm{RC} / \gamma$-ferric oxide $/ \mathrm{PPySSA}$} & First order & $\begin{array}{l}0 \\
1\end{array}$ & $\begin{array}{l}0.048 \\
0.096\end{array}$ & $\begin{array}{l}0.048 \\
0.096\end{array}$ & $\begin{array}{c}0.761 \\
0.9543\end{array}$ \\
\hline & Zero order & $\begin{array}{l}0 \\
1\end{array}$ & $\begin{array}{l}3.81 \\
7.80\end{array}$ & $\begin{array}{l}3.81 \\
7.80\end{array}$ & $\begin{array}{c}0.7584 \\
0.977\end{array}$ \\
\hline & Higuchi & $\begin{array}{l}0 \\
1\end{array}$ & $\begin{array}{l}12.87 \\
25.57\end{array}$ & $\begin{array}{l}12.87 \\
25.57\end{array}$ & $\begin{array}{l}0.8192 \\
0.9959\end{array}$ \\
\hline & Korsmeyer-Peppas & $\begin{array}{l}0 \\
1\end{array}$ & $\begin{array}{l}0.1135 \\
0.246\end{array}$ & & $\begin{array}{c}0.831 \\
0.9971\end{array}$ \\
\hline
\end{tabular}

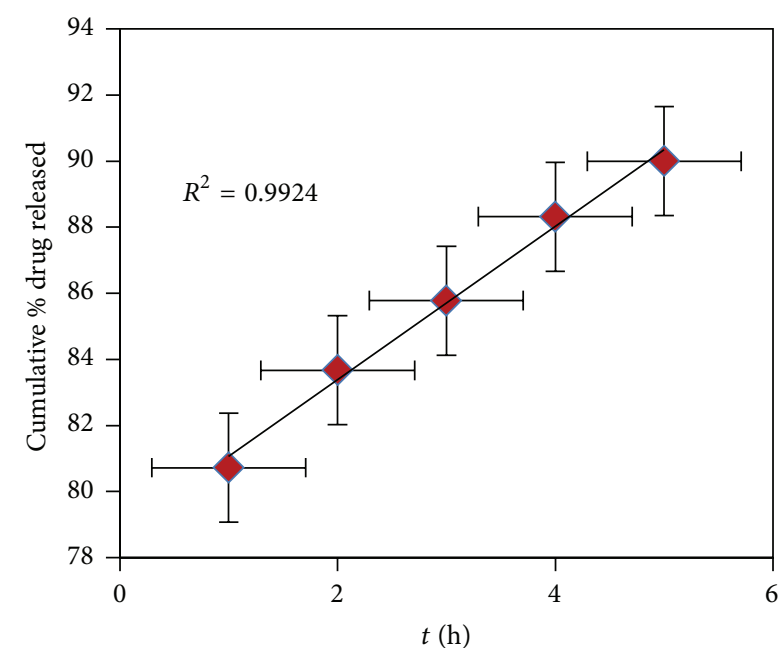

(a)

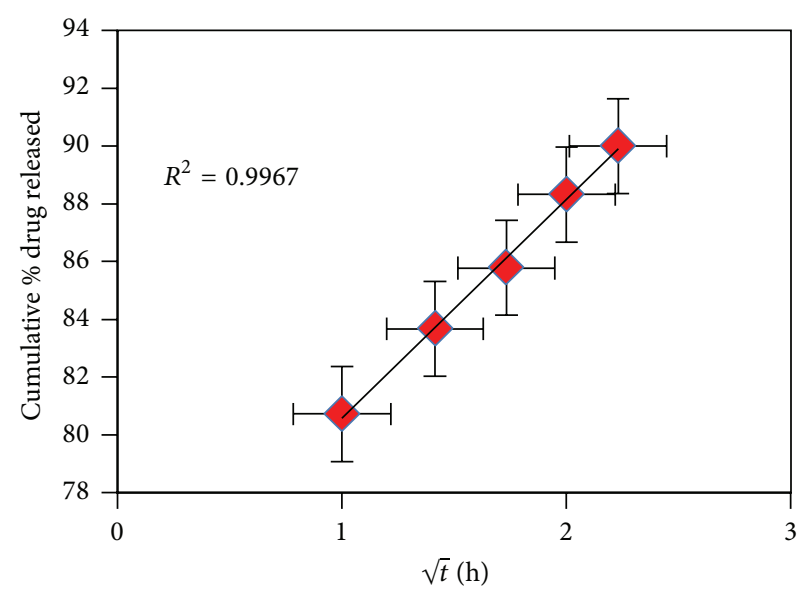

(c)

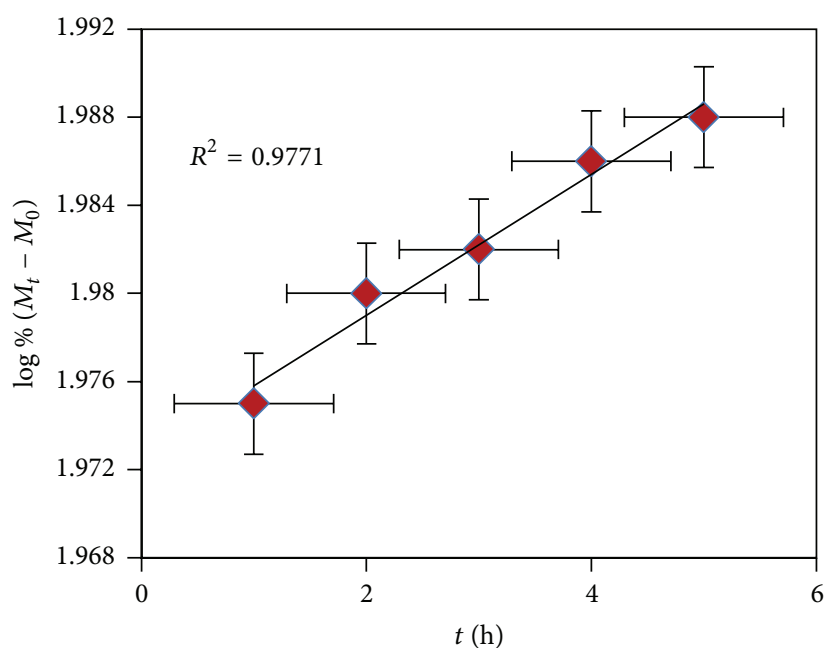

(b)

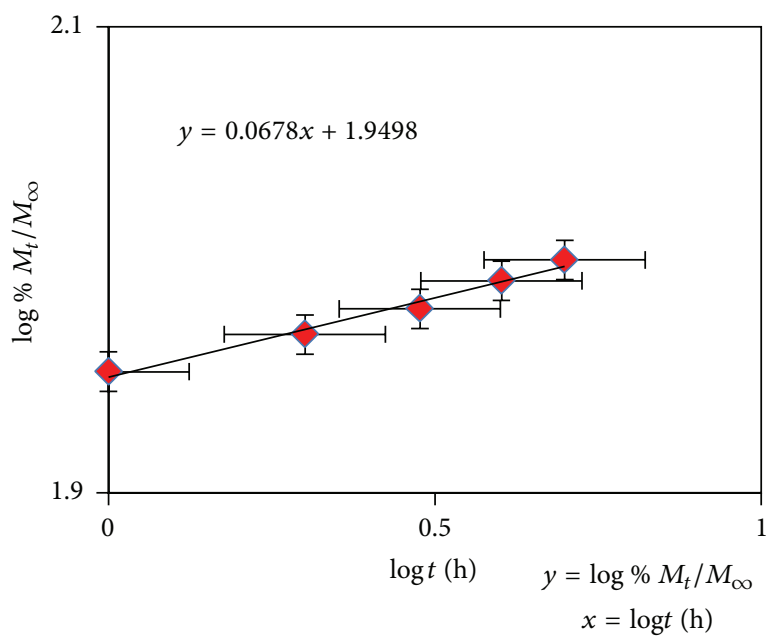

(d)

Figure 7: Plots of (a) zero, (b) first, (c) Higuchi, and (d) Korsmeyer-Peppas release kinetics of SSA from RC/ $\gamma$-Fe ${ }_{2} \mathrm{O}_{3} / \mathrm{PPySSA}$ matrices at ACMF $1.15 \mathrm{KHz}, 0.1 \mathrm{~A}$, and $R^{2}=$ correlation coefficients.

The diffusion coefficients of sulfosalicylic acid from $\mathrm{RC} / \gamma-\mathrm{Fe}_{2} \mathrm{O}_{3} /$ PPySSA matrices are $1.38 \times 10^{-7} \mathrm{~cm}^{2} \mathrm{~s}^{-1}$ in the absence of electric field and $6.66 \times 10^{-7} \mathrm{~cm}^{2} \mathrm{~s}^{-1}$ under electric field strength of $1 \mathrm{~V}$. The diffusion coefficients of sulfosalicylic acid from sulfosalicylic acid-loaded poly(acrylic acid)/polypyrrole blend films in the absence of electric field are one order of magnitude lower compared to the diffusion coefficients of sulfosalicylic acid from the RC/ $\gamma$ $\mathrm{Fe}_{2} \mathrm{O}_{3} /$ PPySSA matrices. For PPy/PAA blend films, the diffusion coefficients of sulfosalicylic acid vary between $1.97 \times 10^{-8}$ 
and $7.30 \times 10^{-7} \mathrm{~cm}^{2} / \mathrm{s}$ under an applied electric field strength of $1 \mathrm{~V}$ [15].

Figure 6 shows a comparison of square-root-of-time dependent release kinetics observed by sample- 1 and sample2. Sample-1 under electric field shows initial fast release of drug delivery due to some loosely held drug and later linearly increases with square-root-of-time. The rate of drug release was linearly increased with square-root-of-time under the electric field strength of $1 \mathrm{~V}$. This result indicates that the drug release mechanism is diffusion controlled. In addition, the presence of polypyrrole helps transporting SSA through the matrices. Here polypyrrole releases drug in response to electrical signal. Polypyrrole chains are expanded when the matrices are under electric field, and free space in the PPy chains is generated; thus, electric field pushes the ionic drug out by the electrostatic force. Sample-2 shows fast release of drug delivery initially and after 3 hours reaches equilibrium values. This is due to the interaction of drug with polypyrrole. The drug molecules diffuse out of the matrices through the concentration gradient effect in the absence of electric field. These results can be compared with the drugdoped (aloin) conductive/hydrogel system poly( $p$-phenylene vinylene)/polyacrylamide (PPV/PAAM) in the absence of an electric field. The diffusion of aloin from the aloin-doped PPV/PAAM hydrogel was delayed in the first 3-14 h. This is due to the ionic interaction between the anionic drug and PPV. After $14 \mathrm{~h}$, aloin could continuously diffuse into the buffer solution through the PAAM matrix [27]. Therefore, these types of matrices cannot be used for the treatment of illness in an emergency care.

Drug release kinetics was determined from $\mathrm{RC} / \gamma$ $\mathrm{Fe}_{2} \mathrm{O}_{3} /$ PPySSA matrices $(2.45 \mathrm{~cm} \times 0.6 \mathrm{~cm}$ with a thickness of $67-70 \mu \mathrm{m}$ ) under AC magnetic field using zero order, first order, and Higuchi, while the mechanism of drug release was determined using Korsmeyer-Peppas model. For zero order, first order, and Higuchi model, the correlation coefficient $\left(R^{2}\right)$ was graphically determined and used to predict the kinetics of drug release from the matrices (Figure 7). According to the plots given in Figure 7, the matrices show square-rootof-time dependent release kinetics as the plot of cumulative $\%$ drug release versus $\sqrt{t}(\mathrm{~h})$ has the highest value of $R^{2}$. The heat produced locally by magnetic particles under alternating current (AC) magnetic field loosens the polymer (polypyrrole) chain surrounding the particles. As a result, the drugs attached to the polypyrrole chain come out to the release medium. In addition, gamma ferric oxide nanoparticles have magnetic properties because of the presence of aligned unpaired electron spins. Their moments align with the direction of the magnetic field while being placed under magnetic field. As a result, it enhances magnetic flux and the rate of drug release [9].

\section{Conclusion}

In this study, regenerated cellulose/ $\gamma$-ferric oxide/polypyrrole matrices were prepared to study the drug release mechanism of the drug under electric and magnetic fields. Under applied electric field, the diffusion coefficient of the drug from the matrices increases with increasing applied electric field strength due to the electrostatic force from electrical potential driving the charged drug to the oppositely charged electrode. In addition, polypyrrole chains are expanded when the matrices are under electric field, and free space in the PPy chains is generated; thus, electric field pushes the ionic drug out by the electrostatic force. The matrices under electric field show initial fast release of drug delivery due to some loosely held drug and later linearly increase with square-rootof-time. The drug release rate can be controlled by applying electric potential and polypyrrole coating on the $\mathrm{RC} / \gamma-\mathrm{Fe}_{2} \mathrm{O}_{3}$ matrices. While considering electrochemical drug delivery, the supply of actuating energy requires either implantation of a battery or electrical leads that cause discomfort to the patient's skin. In this study, these problems were solved as the drug-doped matrices were actuated magnetically. In addition, the matrices under magnetic field showed the same behavior of drug release kinetics as the matrices under the electrochemical potential. Further, the matrices showed fast release of drug; that is, more than $60 \%$ of the loaded drug was released within $1 \mathrm{~h}$, which is required for the treatment of illness in an emergency care.

\section{Conflict of Interests}

The authors declare that there is no conflict of interests regarding the publication of this paper.

\section{Acknowledgments}

The research was financially supported by the Institute of Biomedical Technologies and technically supported by the School of Applied Sciences, Auckland University of Technology, Auckland, New Zealand. The authors are grateful to Senior Research Officer Patrick Conor from Faculty of Design \& Creative Technologies for helping in taking SEM images.

\section{References}

[1] N. M. Elman, H. L. Ho Duc, and M. J. Cima, "An implantable MEMS drug delivery device for rapid delivery in ambulatory emergency care," Biomedical Microdevices, vol. 11, no. 3, pp. 625631, 2009.

[2] J. M. Maloney, S. A. Uhland, B. F. Polito, N. F. Sheppard Jr., C. M. Pelta, and J. T. Santini Jr., "Electrothermally activated microchips for implantable drug delivery and biosensing," Journal of Controlled Release, vol. 109, no. 1-3, pp. 244-255, 2005.

[3] J. Ellisin, in Handbook of Conducting Polymers, T. Skotheim, Ed., p. 501, Marcel Dekker, New York, NY, USA, 1986.

[4] G. Qiu, Q. Wang, and M. Nie, "Polypyrrole- $\mathrm{Fe}_{3} \mathrm{O}_{4}$ magnetic nanocomposite prepared by ultrasonic irradiation," Macromolecular Materials and Engineering, vol. 291, no. 1, pp. 68-74, 2006.

[5] C. C. Berry and A. S. G. Curtis, "Functionalisation of magnetic nanoparticles for applications in biomedicine," Journal of Physics D: Applied Physics, vol. 36, no. 13, pp. R198-R206, 2003.

[6] S. Yun and J. Kim, "A bending electro-active paper actuator made by mixing multi-walled carbon nanotubes and cellulose," 
Smart Materials and Structures, vol. 16, no. 4, pp. 1471-1476, 2007.

[7] W. Wu, Q. He, and C. Jiang, "Magnetic iron oxide nanoparticles: synthesis and surface functionalization strategies," Nanoscale Research Letters, vol. 3, no. 11, pp. 397-415, 2008.

[8] J. Huang, I. Ichinose, and T. Kunitake, "Nanocoating of natural cellulose fibers with conjugated polymer: hierarchical polypyrrole composite materials," Chemical Communications, no. 13, pp. 1717-1719, 2005.

[9] D. L. J. Thorek, A. K. Chen, J. Czupryna, and A. Tsourkas, "Superparamagnetic iron oxide nanoparticle probes for molecular imaging," Annals of Biomedical Engineering, vol. 34, no. 1, pp. 23-38, 2006.

[10] J. J. MacK, B. N. Cox, O. Sudre et al., "Achieving nutrient pumping and strain stimulus by magnetic actuation of tubular scaffolds," Smart Materials and Structures, vol. 18, no. 10, Article ID 104025, 16 pages, 2009.

[11] A. K. Bajpai, S. K. Shukla, S. Bhanu, and S. Kankane, "Responsive polymers in controlled drug delivery," Progress in Polymer Science, vol. 33, no. 11, pp. 1088-1118, 2008.

[12] T. Neuberger, B. Schöpf, H. Hofmann, M. Hofmann, and B. von Rechenberg, "Superparamagnetic nanoparticles for biomedical applications: possibilities and limitations of a new drug delivery system," Journal of Magnetism and Magnetic Materials, vol. 293, no. 1, pp. 483-496, 2005.

[13] J. Song, Z. Y. Ma, C. Li, and R. J. Wu, "Synthesis of ferric oxide nanoparticles with controllable crystal phases by salt-assisted combustion method," Journal of Inorganic Materials, vol. 25, no. 7, pp. 780-784, 2010.

[14] C. L. McCormick, P. A. Callais, and B. H. Hutchinson Jr., "Solution studies of cellulose in lithium chloride and N,Ndimethylacetamide," Macromolecules, vol. 18, no. 12, pp. 23942401, 1985.

[15] P. Chansai, A. Sirivat, S. Niamlang, D. Chotpattananont, and K. Viravaidya-Pasuwat, "Controlled transdermal iontophoresis of sulfosalicylic acid from polypyrrole/poly(acrylic acid) hydrogel," International Journal of Pharmaceutics, vol. 381, no. 1, pp. 25-33, 2009.

[16] J. Wu and Q. Yuan, "Gas permeability of a novel cellulose membrane," Journal of Membrane Science, vol. 204, no. 1-2, pp. 185-194, 2002.

[17] M. Cristina, Z. Aránzazu, and M. L. José, "Critical factors in the release of drugs from sustained release hydrophilic matrices," Journal of Controlled Release, vol. 154, no. 1, pp. 2-19, 2011.

[18] S. Basavaraja, H. Vijayanand, A. Venkataraman, U. P. Deshpande, and T. Shripathi, "Characterization of $\gamma-\mathrm{Fe}_{2} \mathrm{O}_{3}$ nanoparticles synthesized through self-propagating combustion route," Synthesis and Reactivity in Inorganic, Metal-Organic and NanoMetal Chemistry, vol. 37, no. 6, pp. 409-412, 2007.

[19] I. Hamley, "Nanotechnology with soft materials," Angewandte Chemie International Edition, vol. 42, no. 15, pp. 1692-1712, 2003.

[20] F. A. Miller and C. H. Wilkins, "Infrared spectra and characteristic frequencies of inorganic ions: their use in qualitative analysis," Analytical Chemistry, vol. 24, no. 8, pp. 1253-1294, 1952.

[21] C.-S. Wu, F.-Y. Lin, C.-Y. Chen, and P. P. Chu, "A polyvinyl alcohol/ $p$-sulfonate phenolic resin composite proton conducting membrane," Journal of Power Sources, vol. 160, no. 2, pp. 1204-1210, 2006.

[22] G.-L. Chen and W.-H. Hao, "In vitro performance of floating sustained-release capsule of verapamil," Drug Development and Industrial Pharmacy, vol. 24, no. 11, pp. 1067-1072, 1998.
[23] T. Higuchi, "Rate of release of medicaments from ointment bases containing drugs in suspension," Journal of Pharmaceutical Sciences, vol. 50, pp. 874-875, 1961.

[24] R. W. Korsmeyer, R. Gurny, E. Doelker, P. Buri, and N. A. Peppas, "Mechanisms of solute release from porous hydrophilic polymers," International Journal of Pharmaceutics, vol. 15, no. 1, pp. 25-35, 1983.

[25] M. V. Shah, M. D. de Gennaro, and H. Suryakasuma, "An evaluation of albumin microcapsules prepared using a multiple emulsion technique," Journal of Microencapsulation, vol. 4, no. 3, pp. 223-238, 1987.

[26] R. A-sasutjarit, A. Sirivat, and P. Vayumhasuwan, "Viscoelastic properties of Carbopol 940 gels and their relationships to piroxicam diffusion coefficients in gel bases," Pharmaceutical Research, vol. 22, no. 12, pp. 2134-2140, 2005.

[27] S. Niamlang, T. Buranut, A. Niansiri, and A. Sirivat, "Controlled aloin release from crosslinked polyacrylamide hydrogels: effects of mesh size, electric field strength and a conductive polymer," Materials, vol. 6, no. 10, pp. 4787-4800, 2013. 

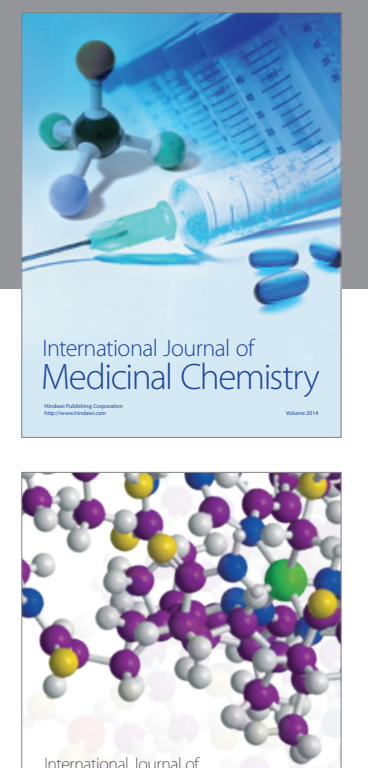

\section{Carbohydrate} Chemistry

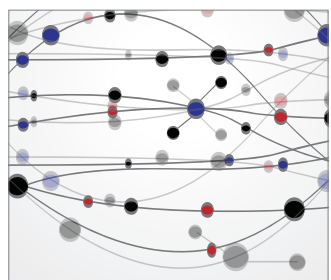

The Scientific World Journal
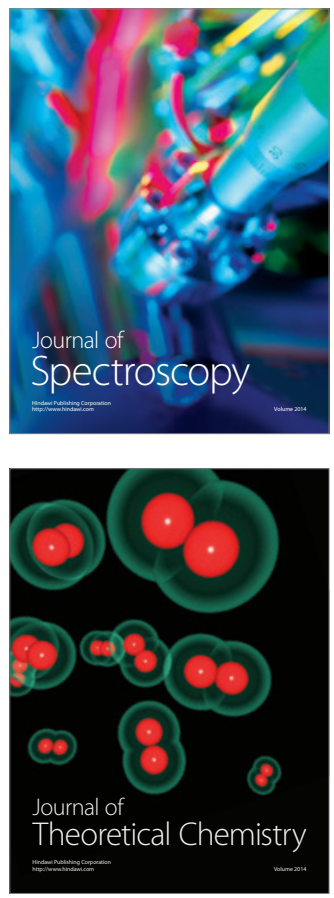
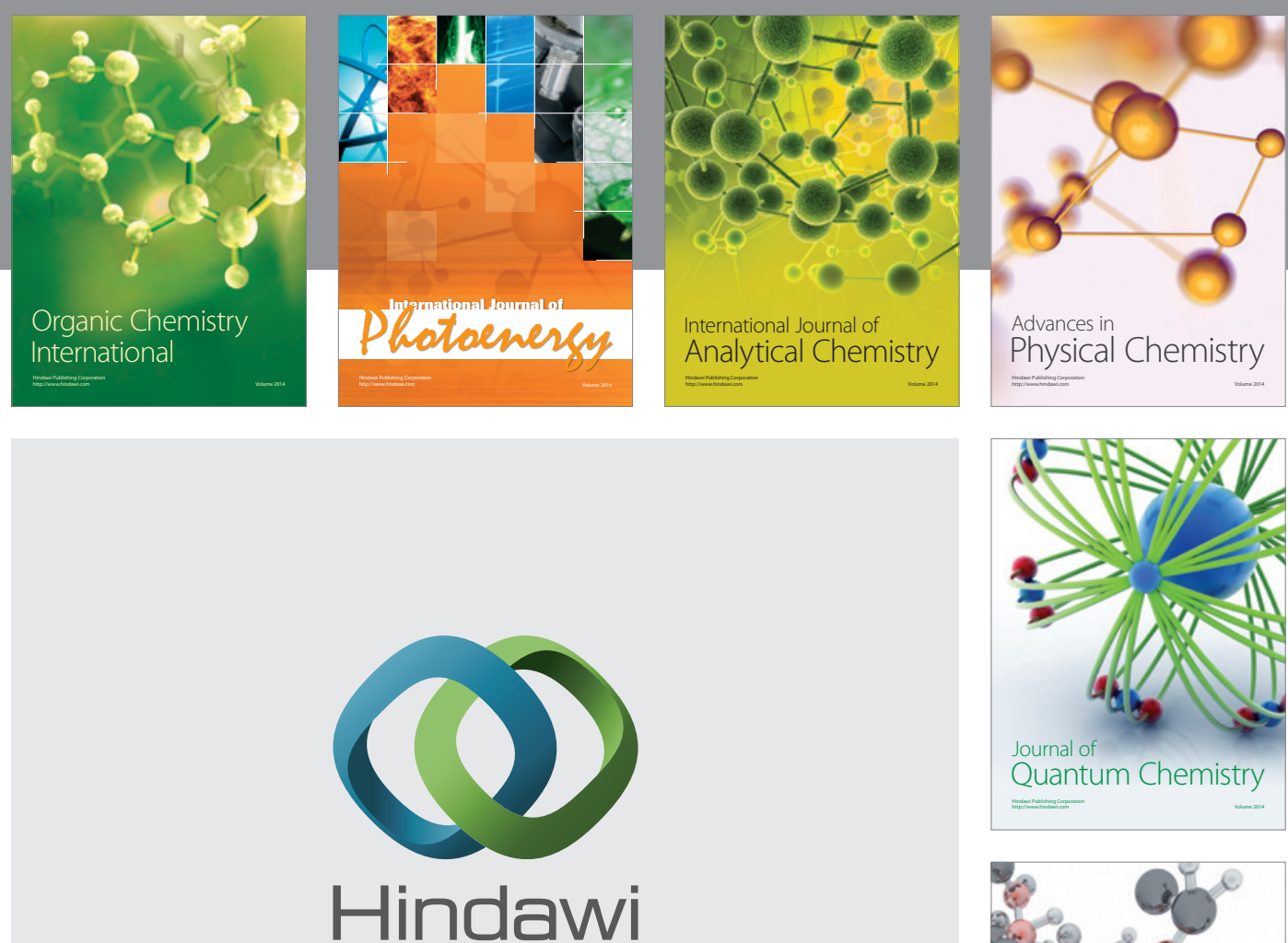

Submit your manuscripts at

http://www.hindawi.com

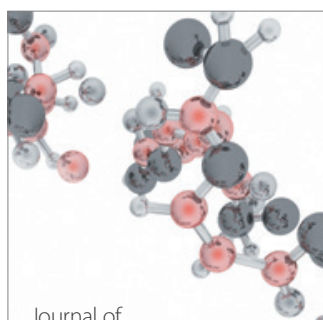

Analytical Methods

in Chemistry

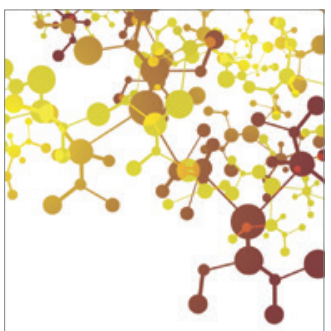

Journal of

Applied Chemistry

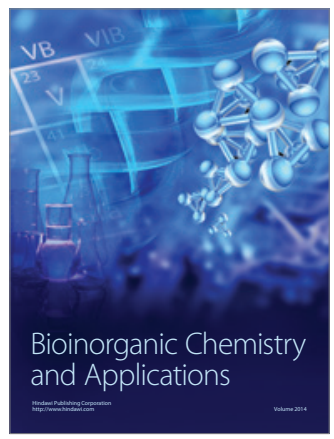

Inorganic Chemistry
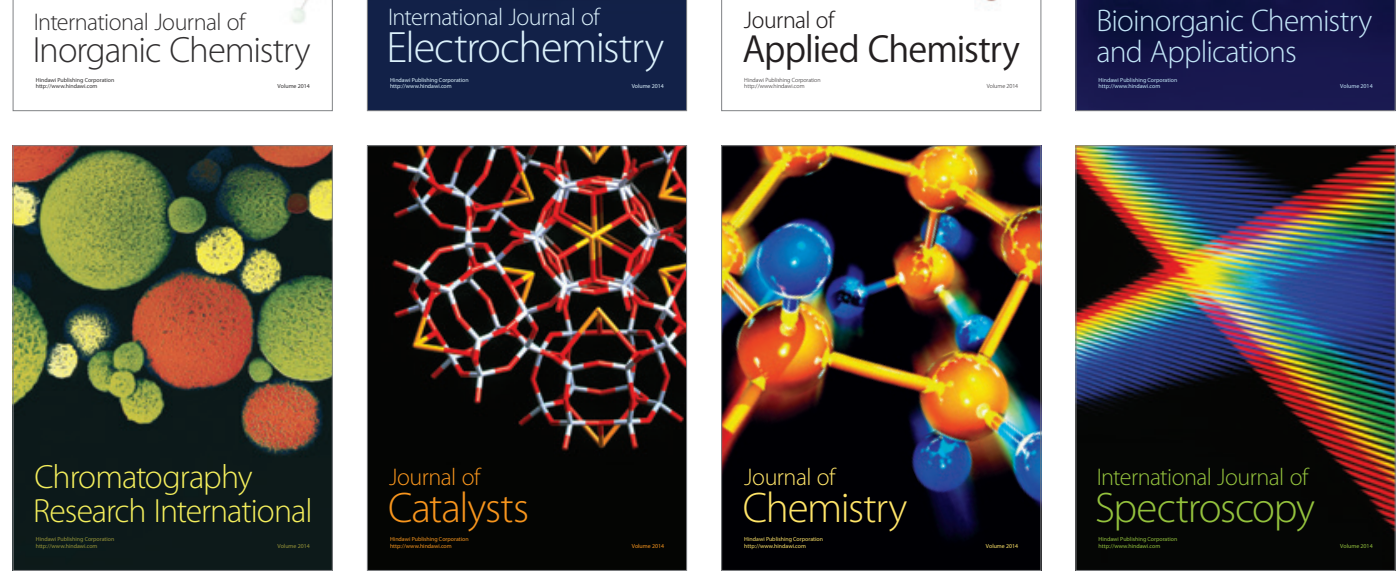